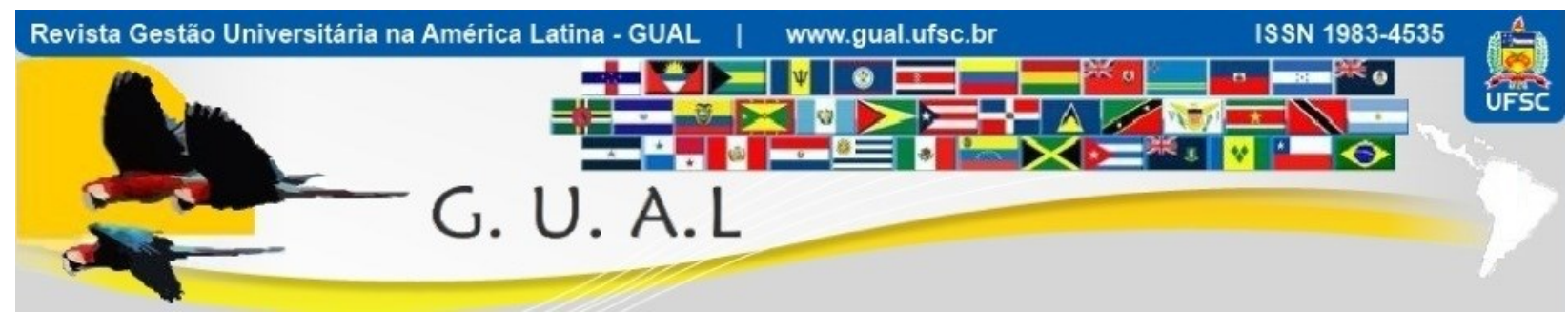

DOI: http://dx.doi.org/10.5007/1983-4535.2014v7n1p213

\title{
A "DOR DO CRESCIMENTO": UM ESTUDO SOBRE O NÍVEL DE ESTRESSE EM PÓS-GRADUANDOS DE CONTABILIDADE
}

\author{
THE "PAIN GROWTH": A STUDY OF THE LEVEL OF STRESS IN \\ POSTGRADUATES ACCOUNTING
}

Stella Maris Lima Altoé, Doutoranda

Universidade Federal do Paraná - UFPR stella.altoe@gmail.com

Adriana Casavechia Fragalli, Mestranda Universidade Federal do Paraná - UFPR adriana.fragalli@gmail.com

Márcia Maria dos Santos Bortolocci Espejo, Doutora

Universidade Federal do Paraná - UFPR marciabortolocci@ufpr.br

Recebido em 12/julho/2013

Aprovado em 15/outubro/2013

Sistema de Avaliação: Double Blind Review

Esta obra está sob uma Licença Creative Commons Atribuição-Uso. 


\title{
RESUMO
}

O aumento do número de Programas de pós-graduação Scricto Sensu em Ciências Contábeis tem impulsionado os discentes a ingressarem no ambiente acadêmico. Em paralelo a esta inserção constata-se que o conceito dos Programas, definido pela CAPES, está principalmente vinculado ao número de publicação em eventos e periódicos, o que por sua vez, faz com que os Programas de pós-graduação, em busca de boas avaliações, exerçam pressão em seus alunos a trabalharem intensamente no desenvolvimento de pesquisas. Neste sentido o propósito deste estudo é identificar o nível de estresse em estudantes de mestrado e doutorado em Contabilidade no Brasil, no sentido de constatar em qual estágio de estresse se encontram, conforme prevê o Inventário de Sintomas de Stress de Lipp. Trata-se de uma pesquisa descritiva com abordagem quantitativa realizada com 265 pós-graduandos em Ciências Contábeis no Brasil. Para a coleta de dados utilizou-se um instrumento específico com questões relativas as características pessoais e questões referentes ao Inventário de Sintomas de Stress de Lipp, que foi disponibilizado à população alvo durante o mês de Janeiro de 2013, por meio do aplicativo eletrônico Google Docs. Após a análise descritiva e estatística com uso do Microsoft Excel e SPSS, concluiu-se que os sintomas de estresse mais apresentados foram: tensão muscular; insônia; cansaço constante; esquecimento; angústia ou ansiedade diária; e irritabilidade sem causa aparente. Dentre os pós-graduandos que apresentaram estresse, a maioria são mestrandos, sendo as mulheres mais estressadas do que os homens.

Palavras-Chave: Estresse. Pós-graduandos. Contabilidade. Sintomas de Estresse. Fases de Estresse.

\begin{abstract}
The increase in the number of graduate programs in Accounting Scricto Sensu has driven students to join in the academic environment. In parallel to this insertion appears that the concept of programs, defined by CAPES, is mainly linked to the number of events and publication in journals, which in turn causes the graduate programs in search of good assessments, putting pressure on their students to work intensively on the development of research. In this sense, the purpose of this study is to identify the level of stress in students of master's and doctorate in Accounting in Brazil, in order to realize at what stage of stress are as provided by the Inventory of Stress Symptoms Lipp. This is a descriptive research with quantitative approach with 265 graduate students in Accounting in Brazil. For data collection we used a specific instrument with questions concerning personal characteristics and issues related to Inventory Lipp Stress Symptoms, which was made available to the target population during the month of January 2013, through the electronic application Google Docs . After the descriptive and statistical analysis using Microsoft Excel and SPSS, it was concluded that the stress symptoms were presented more: muscle tension, insomnia, constant fatigue, forgetfulness, anxiety or daily anxiety, and irritability without apparent cause. Among the graduate students who had stress, most are masters, and women are more stressed than men.
\end{abstract}

Keywords: Stress. Postgraduates. Accounting. Symptoms of Stress. Stages of Stress. 


\section{INTRODUÇÃO}

Atualmente a pós-graduação é uma alternativa atraente para a capacitação dos profissionais, uma vez que o mercado de trabalho seja no âmbito acadêmico ou profissional está cada vez mais competitivo (SCHILLINGS, 2005). O ingresso à pós-graduação, sobretudo em cursos Scricto Sensu, reflete em mudanças de hábitos e rotinas, e consequente adaptação do ser humano. Processos de adaptação muitas vezes impactam em estresse em função do dispêndio de energia demandado, o que pode ocasionar doenças referentes à redução de imunidade (SILLAS et al, 2011).

Nas últimas décadas o número de Programas de pós-graduação Stricto Sensu em Ciências Contábeis no Brasil aumentou, e juntamente com esta expansão os Programas têm buscado elevar o montante de publicações, tendo em vista que a Coordenação de Aperfeiçoamento de Pessoal de Nível Superior (CAPES) vincula o seu conceito ao número de produções científicas dele decorrentes (SOARES; RICHARTZ; MURCIA, 2011). Desta forma, tal fato pode desencadear em estresse tanto para o docente, que é pressionado por agentes externos, quanto para o discente que precisa contribuir para o desempenho do Programa no qual está inserido, especialmente se houver a condição de bolsista, em função das maiores exigências desta função.

Considerando que os pós-graduandos estão suscetíveis a uma alta carga de estudos e que este contexto exige constante adaptação, pretende-se identificar o estágio e os sintomas de estresse predominantes em estudantes de mestrado e doutorado de Contabilidade do Brasil, relacionando o estresse com suas características pessoais. Para tanto, utilizou-se como norteadora do estudo a seguinte questão de pesquisa: Em qual fase de estresse se encontram os estudantes de mestrado e doutorado em Contabilidade do Brasil?

A relevância da pesquisa consiste em evidenciar se os futuros mestres e doutores em Contabilidade estão sujeitos ao estresse ao longo do curso, uma vez que o ambiente acadêmico, decorrente das pressões e cobranças, pode ser um fator propício ao aparecimento do estresse (MALAGRIS et al, 2009). Neste sentido, pressupondo que os hábitos estressores podem ser modificados, a identificação dos agentes causadores do estresse na pós-graduação poderá contribuir para sua redução; dessa forma, espera-se um aumento na qualidade de vida dos discentes, impactando em melhores desempenho, que por sua vez, podem favorecer na performance dos Programas de pós-graduação. Possatti e Dias (2002) atribuem importância a estudos relacionados ao estresse devido ao seu alto custo social, seja pela baixa produtividade 
por aqueles que apresentam dificuldades para dormir, como também pelo grande número de consultas médicas realizadas em função dos diferentes sintomas de estresse.

Para o alcance do objetivo proposto, este artigo está estruturado em cinco seções. Após a introdução, é apresentado o referencial teórico, com abordagem da pós-graduação em Contabilidade no Brasil e o estresse. Na sequência, a estrutura metodológica, seguida pela descrição e análise dos resultados. Finalizando o texto, são apresentadas as considerações finais e, por fim, as referências.

\section{PÓS-GRADUAÇÃO EM CONTABILIDADE NO BRASIL}

A pós-graduação Stricto Sensu em Contabilidade teve início no Brasil por volta de 1970 com o programa de mestrado oferecido pela FEA/USP. Este programa foi o único no Brasil durante sete anos, sendo que em 1978 a mesma instituição implantou o primeiro programa de doutorado em Contabilidade (MARTINS; IUDÍCIBUS, 2007). Desde então, o número de Programas de mestrado e doutorado em Contabilidade vem crescendo notavelmente, chegando a um total de 18 Programas avaliados pela CAPES no triênio 20042006 (CAPES, 2013b).

A maioria dos cursos de pós-graduação em Ciências Contábeis concentra-se na modalidade acadêmica, no entanto, um estudo realizado por Velloso (2004) demonstra que mestres e doutores da área profissional, assim considerados os administradores, médicos, economistas, psicólogos, entre outros, trabalham nas mais diversas áreas, sendo que cerca de $20 \%$ destes profissionais exercem funções autônomas, trabalhando em escritórios ou consultórios. Logo, entende-se que uma grande parte dos pós-graduandos não seguem carreira acadêmica, inclusive na área contábil.

Observa-se também que a maioria dos Programas de pós-graduação em Contabilidade são oferecidos por universidades públicas, o que também ocorre em outras áreas (VELLOSO, 2004). Estes Programas, sejam públicos ou privados, são regulamentados pela CAPES, Coordenação de Aperfeiçoamento de Pessoal de Nível Superior, que instituiu em 1976 o Sistema de Avaliação da pós-graduação e desde então vem cumprindo papel de fundamental importância para o desenvolvimento da pós-graduação e da pesquisa científica e tecnológica no Brasil (CAPES, 2013a).

O sistema de avaliação da CAPES busca um padrão de excelência acadêmica para os mestrados e doutorados nacionais por meio de cinco quesitos atualmente observados: 
proposta do programa; corpo docente; corpo discente, teses e dissertações; produção intelectual; e, inserção social. A "proposta do programa" não possui atribuição de peso no processo avaliativo embora impacte em todos os demais quesitos; já os demais itens possuem, respectivamente, 30\%, 25\%, 35\% e 10\% (CAPES, 2013a). Como se pode observar, a produção intelectual é um fator de extrema importância para o sucesso do programa, o que exige, tanto de alunos como de professores, muita dedicação, o que por sua vez pode gerar cansaço físico e/ou emocional.

De acordo com Igarashi et al (2008, p. 122), esta avaliação cumpre os seguintes propósitos:

\begin{abstract}
Impulsionar o sistema de pós-graduação no contexto nacional; oferecer a cada programa um parecer criterioso a respeito de seu desempenho, de forma a auxiliar na promoção de seu aprimoramento; montar um banco de dados sobre a situação da pós-graduação no Brasil; estabelecer um padrão de qualidade para os programas de pós-graduação no Brasil; oferecer subsídios para informar os pareceres sobre criação e renovação dos cursos de mestrado e doutorado brasileiros; oferecer subsídios para a definição de políticas de desenvolvimento da pós-graduação.
\end{abstract}

Visando um bom conceito na avaliação da CAPES, os Programas realizam processos seletivos buscando estudantes qualificados. Neste processo, a análise do currículo é utilizada pela grande maioria, pois a produção de artigos é um aspecto relevante a ser analisado. No Quadro 1 estão resumidos os processos seletivos dos Programas de pós-graduação Stricto Sensu em Contabilidade nacionais, sendo as informações encontradas em seu respectivos sites.

Os estudantes que decidem ingressar num curso de mestrado ou doutorado, além de enfrentarem o processo seletivo, passam por mudanças de hábitos e rotinas que muitas vezes provocam o estresse (SILLAS et al, 2011). Dessa forma nota-se que o estudo não é uma atividade fácil, sendo preciso dispor, além de tempo e dedicação, muita energia. Por esse motivo, identificar o estágio e os sintomas de estresse poderá promover ações que minimizem esse efeito, promovendo maior qualidade nos estudos. 


\begin{tabular}{|c|c|}
\hline МA & VO \\
\hline UFES & Teste ANPAD; análise de curriculum vitae (plataforma lattes) e projeto de estudo/pesquisa. \\
\hline FUCAPE & Análise de curriculum vitae; prova objetiva; entrevista com a comissão de pós-graduação. \\
\hline UFMG & $\begin{array}{l}\text { Teste ANPAD; prova de conhecimentos específicos; análise do histórico escolar e } \\
\text { curriculum vitae. }\end{array}$ \\
\hline UFPE & $\begin{array}{l}\text { Prova de conhecimentos gerais; prova de conhecimentos específicos; avaliação do } \\
\text { currículum vitae e defesa do pré-projeto de pesquisa. }\end{array}$ \\
\hline UFRJ & $\begin{array}{l}\text { Teste ANPAD; prova de conhecimentos específicos; avaliação do currículo e do projeto de } \\
\text { pesquisa. }\end{array}$ \\
\hline UERJ & $\begin{array}{l}\text { Teste ANPAD; prova escrita sem consulta; entrevista, análise do anteprojeto de pesquisa e } \\
\text { currículo. }\end{array}$ \\
\hline UNISINOS & $\begin{array}{l}\text { Teste ANPAD; análise e avaliação da documentação; prova de conhecimentos específicos } \\
\text { abrangendo temas da linha de pesquisa de interesse; entrevista com selecionados. }\end{array}$ \\
\hline & $\begin{array}{l}\text { Mestrado: Teste ANPAD; análise do curriculum vitae; análise do histórico escolar da } \\
\text { graduação; análise do plano de trabalho e do projeto de dissertação; entrevista. }\end{array}$ \\
\hline FURB & $\begin{array}{l}\text { Doutorado: Teste ANPAD; análise do curriculum vitae; análise do histórico escolar da } \\
\text { graduação e do mestrado; análise do plano de trabalho e do projeto de tese; prova } \\
\text { de conhecimentos específicos na respectiva área de concentração indicada na inscrição; } \\
\text { entrevista com os candidatos selecionados. }\end{array}$ \\
\hline UPM & e de proficiência; entrevista. \\
\hline UNIFECAP & $\begin{array}{l}\text { Teste ou realização de prova interna aplicada pela FECAP; entrevista dos candidatos } \\
\text { aprovados na primeira fase. }\end{array}$ \\
\hline PUC/SP & $\begin{array}{l}\text { Análise de documentação; prova de raciocínio lógico e quantitativo; pré-projeto de pesquisa } \\
\text { e entrevista. }\end{array}$ \\
\hline UFBA & $\begin{array}{l}\text { Prova objetiva; arguição sobre memorial e projeto e avaliação das informações adicionais } \\
\text { exigidas - memorial descritivo, projeto de pesquisa proposto para o mestrado e currículo da } \\
\text { plataforma lattes atualizada. }\end{array}$ \\
\hline UFPR & $\begin{array}{l}\text { Teste ANPAD; prova de conhecimentos específicos; prova de redação; análise de currículo } \\
\text { e pré-projeto. }\end{array}$ \\
\hline UFSC & Teste ANPAD; prova escrita; análise curricular; apresentação do pré-projeto. \\
\hline UNB & $\begin{array}{l}\text { Teste ANPAD; prova escrita; prova oral; avaliação do pré-projeto; prova de avaliação de } \\
\text { histórico escolar e currículo. }\end{array}$ \\
\hline UFAM & $\begin{array}{l}\text { Prova de conhecimentos em contabilidade e controladoria; Teste ANPAD; curriculum vitae } \\
\text { e proposta de pré-projeto. }\end{array}$ \\
\hline \multirow[b]{2}{*}{ USP } & $\begin{array}{l}\text { Mestrado: Teste ANPAD; provas específicas de contabilidade gerencial e contabilidade } \\
\text { societária; entrevista com os professores do PPGCC. }\end{array}$ \\
\hline & $\begin{array}{l}\text { Doutorado: Teste ANPAD; provas específicas de contabilidade gerencial e contabilidade } \\
\text { societária; análise do projeto de tese; entrevista com os professores do PPGCC }\end{array}$ \\
\hline USP/RP & n ou mais dos testes ANPAD, GRE® ou GMAT®; análise \\
\hline
\end{tabular}

Quadro 1 Processo seletivo dos Programas de pós-graduação Stricto Sensu em Contabilidade. Fonte: Os autores (2013).

\section{ESTRESSE}

De acordo com Lipp (2000a) o estresse é um termo de origem latina. Suas discussões iniciam-se em 1926 com o Dr. Hans Selye, considerado o primeiro cientista a utilizar o termo, descrevendo-o como um estado de tensão patogênico do organismo. Arantes e Vieira (2002) complementam que o trabalho The general adaptation syndrome and the diseases of adaptation, foi o primeiro trabalho do médico. Ressalta-se também, que o termo "estresse" já 
foi incorporado a língua portuguesa, no entanto, os especialistas ainda preferem utilizar a terminologia "stress" (LIPP, 2000a). Nesta pesquisa utilizou-se a palavra estresse para referirse ao termo.

Margis et al (2003) descrevem três grupos de situações ambientais que podem ocasionar estresse. $\mathrm{O}$ primeiro grupo compreende as mudanças na vida, como iniciar um novo emprego, casar-se ou separar-se, o nascimento de um filho. A avaliação destas mudanças eventos estressores - pode possibilitar a identificação da frequência com que o sujeito desencadeia uma resposta ao estresse. Neste sentido, algumas reações do organismo se destacam diante dos agentes estressores: ações psicológicas e fisiológicas são consideradas como respostas ao estresse (SAVÓIA, 1999).

Eventos menores como perder objetos, esperar em filas, o som do despertador ou o barulho de vizinhos, caracterizam o segundo grupo de situações que podem motivar o estresse. No entanto, ressalta-se que o nível de estresse neste grupo é menor (MARGIS et al, 2003). Savóia (1999) complementa que nesta etapa, os estímulos externos são relevantes para a concepção do estresse.

O terceiro grupo refere-se às situações crônicas, que são provenientes de relacionamentos conturbados (MARGIS et al, 2003). Neste nível acontece a interação dos dois grupos anteriores, a partir da combinação dos aspectos internos referentes ao organismo e dos externos. Observa-se que grande parte das respostas ao estresse por parte do indivíduo é auto produzida (SAVÓIA, 1999). Savóia (1999) ressalta que o estresse proveniente da percepção do indivíduo ao ambiente social é denominado de estresse psicossocial.

Neste sentido, o estresse provoca a ruptura na sintonia interna do organismo, provocando em alguns casos falhas de memória, desgaste físico e mental. $\mathrm{O}$ estresse quando presente em excesso pode originar risco às pessoas (MALAGRIS; FIORITO, 2006). Salientase que se nada é feito para normalizar a situação, doenças como gripe, gastrite, problemas dermatológicos podem surgir (LIPP, 2000b). Portanto, o estresse é proveniente da interação entre características pessoais e externas oriundas do meio, assim fontes internas e externas podem favorer ao estresse (MARGIS et al, 2003).

Os estressores ou as fontes de estresse são tidos como os fatores que causam o estresse, que podem ser classificados como: fontes externas e fontes internas. As fontes externas são oriundas de fatos externos ao organismo, como os que relacionam "[...] a profissão, a falta de dinheiro, brigas, assalto, perdas, falecimento" (LIPP, 2000b, p. 18). Por 
outro lado, os agentes internos de estresse baseiam-se nas crenças, valores, maneira do ser humano agir, conforme seus princípios (LIPP, 2000b).

Selye (1956) segrega o estresse em três fases: i) fase de alerta; ii) fase de resistência e, iii) fase de exaustão. Lipp (2000a) ainda identificou mais uma fase denominada "quase exaustão", que se concentra entre as fases de resistência e exaustão. Na primeira fase denominada de alerta, o indivíduo vivencia a situação estressora, o que provoca um desequilíbrio interno e as seguintes características se sobressaem: suadores excessivos, taquicardia, respiração acelerada e picos de hipertensão. Na segunda fase definida como resistência, o organismo busca recuperar o desequilíbrio proveniente da fase 1 (MALAGRIS; FIORITO, 2006). Lipp e Malagris (2001) destacam que cansaço excessivo, falhas de memória e dúvidas pessoais são alguns dos sintomas sentidos pelo ser humano nesta fase. Caso o organismo não recupere o desgaste oriundo da segunda fase, doenças começam a surgir (PERES, 2008); a partir deste momento o indivíduo vivencia a terceira fase, a exaustão. $\mathrm{Na}$ fase de quase-exaustão idealizada por Lipp, o humor do indivíduo pode variar entre os momentos agradáveis e desagradáveis (VIEIRA; ALVES; SUCCAR JUNIOR, 2012).

O estresse tem sido tema de estudos relacionados a diversos ramos de atuação profissional tais como: empresarial, educacional, industrial e da saúde (MALAGRIS; FIORITO, 2006). Langston e Cantor (1989), em seus estudos com universitários, verificaram como o processo de transição do ensino médio para a universidade pode ser "doloroso" para os estudantes. No estudo foram considerados aspectos relacionados à responsabilidade, ansiedade e competitividade, fatores estes que podem contribuir para o estresse.

O foco da investigação de Calaias, Andrade e Lipp (2003) foi a frequência e os sintomas do estresse, físicos ou psicológicos, em adultos e jovens, com relação ao sexo e período escolar. A avaliação do estresse deu-se a partir do Inventário de Sintomas de Stress de Lipp. Os achados indicam que as mulheres apresentaram maior nível de estresse em todos os grupos avaliados, sendo que o excesso de sensibilidade emotiva e irritabilidade foram os sintomas que prevaleceram. Além disso, verificou-se que o estresse era maior durante o período do vestibular, sendo este um fator estressor de grande parte dos jovens.

O nível de estresse também foi avaliado em técnicos da área de saúde do Rio de Janeiro. A mensuração foi feita a partir de questionário baseado no Inventário de Sintomas de Stress para Adultos de Lipp. Os resultados sugerem um índice de 82,3\% de estresse para os participantes, sendo que $83 \%$ das mulheres e $66 \%$ dos homens foram considerados 
estressados. Portanto, o estudo contribuiu para a qualidade de vida e atuação destes profissionais de saúde (MALAGRIS; FIORITO, 2006).

A presença do estresse no mestrado foi tema de pesquisa na Universidade Federal de Sergipe. A amostra da pesquisa contou com 27 mestrandos em ciências da saúde, sendo composta por 16 mulheres e 11 homens. O Inventário de Stress para adultos de Lipp, a Escala de Modos de Enfrentamento de Problemas e um questionário foram utilizados para mensurar o estresse. Os resultados indicam que $40,7 \%$ dos pesquisados apresentaram estresse, havendo associação entre estresse e sexo, onde as mulheres se apresentaram mais vulneráveis (SANTOS; ALVES JUNIOR, 2007). Diferentes autores mencionam que as mulheres vivenciam maiores níveis de estresse do que os homens, principalmente pela multiplicidade de papéis exercidos por estas (CALAIAS; ANDRADE; LIPP, 2003, POSSATTI; DIAS, 2002).

Vieira, Alves e Succar Junior (2012), identificaram o grau e os sintomas de estresse nos contabilistas registrados junto ao Conselho Regional de Contabilidade do Estado do Rio de Janeiro. Os achados evidenciam que 50\% destes profissionais não apresentaram estresse, $35 \%$ situam-se na fase de resistência, $13 \%$ na fase de exaustão, sendo que os sintomas mais recorrentes foram os sintomas físicos.

Para Santos e Alves Junior (2007) é importante que haja pesquisas que investiguem níveis de estresse na pós-graduação, sobretudo no mestrado. Os autores alegam que o estresse pode impactar no desempenho do mestrando, argumentando que o ingresso na pós-graduação - mestrado - pode ser um possível evento macro-estressor, pressupondo que diversas adaptações serão necessárias. Os autores ainda salientam que no cotidiano do mestrando eventos micro-estressores tendem a ser acumulados em função das múltiplas atividades que o aluno está inserido.

Nos Programas de pós-graduação, os seminários fazem parte da rotina dos mestrandos, cujos propósitos são relacionados à introdução do aluno a pesquisa, leituras especializadas e produção de conhecimento. Considerando que os assuntos abordados em cada seminário são específicos, este pode se caracterizar como um evento estressor focalizado; por outro lado, se o mestrando compreender adequadamente o conteúdo de sua apresentação poderá ficar satisfeito e consequentemente aperfeiçoar seu conhecimento enquanto aluno de pós-graduação (TRZESNIAK, 2004). 
Voltarelli (2002) destaca que as exigências para produção acadêmica, dedicação exclusiva, remuneração não significativa, são fatores que podem desencadear o estresse, à medida que levam ao esgotamento mental e surgimento de inconvenientes a saúde. Portanto, tendo em vista que o estresse em alguns casos pode impactar em problemas a saúde, este estudo analisa quais são os principais sintomas e o nível de estresse apresentados por mestrandos e doutorandos em Ciências Contábeis. Entende-se que, se as causas do estresse forem identificadas, será possível amenizar a ocorrência do mesmo, o que poderá favorecer o desempenho dos alunos e consequentemente dos Programas.

\section{METODOLOGIA}

A pesquisa exploratória teve por objetivo identificar em qual fase de estresse se encontram os mestrandos e doutorandos em Ciências Contábeis do Brasil. Desta forma, classifica-se como um estudo descritivo, tendo em vista que busca identificar as particularidades do público-alvo referentes ao estresse. Quanto à dimensão temporal, definese como um estudo transversal, sendo a investigação realizada em um recorte específico. A abordagem do problema classifica-se como um estudo ex post fact, em que as variáveis da amostra não intencional não sofreram intervenção dos pesquisadores (COOPER; SCHINDLER, 2003).

Para atender ao objetivo do estudo, foi elaborado um quadro de constructo e definições operacionais, fundamentado no referencial teórico (Quadro 2).

\begin{tabular}{|l|l|}
\hline Aspectos Pessoais & $\begin{array}{l}\text { Foram analisadas questões relativas a gênero, idade, situação conjugal, lazer e } \\
\text { número de filhos dos mestrados e doutorandos em Ciências Contábeis. }\end{array}$ \\
\hline $\begin{array}{l}\text { Aspectos do Curso de } \\
\text { Pós-Graduação }\end{array}$ & $\begin{array}{l}\text { Neste constructo foi identificado se o curso de pós-graduação é oriundo de IES } \\
\text { pública ou privada, estágio que o discente se encontra no curso, se o mesmo é } \\
\text { bolsista ou desenvolve outras atividades. }\end{array}$ \\
\hline Estresse & $\begin{array}{l}\text { Foram elencadas duas variáveis distintas para análise deste constructo, as fases de } \\
\text { estresse }- \text { alerta, resistência, quase-exaustão e exaustão - e os sintomas do } \\
\text { estresse que podem ser provenientes de características físicas ou psicológicas. }\end{array}$ \\
\hline
\end{tabular}

Quadro 2 Constructo e definições operacionais.

Fonte: Adaptado de Sillas (2011).

Após contato telefônico com os Programas de pós-graduação em Ciências Contábeis para esclarecimento sobre o propósito da pesquisa, foram enviados e-mails aos Programas solicitando o encaminhamento do mesmo aos alunos de mestrado e/ou doutorado. Ao final, obteve-se respostas de 12 Programas, os quais possuíam um total de 690 alunos inscritos, sendo 516 mestrandos e 174 doutorandos, formado assim a população-alvo. 
O instrumento para a coleta de dados foi disponibilizado via internet por meio do Google Docs e esteve à disposição dos respondentes durante o mês de Janeiro de 2013. Ao final, foi obtida uma amostra não intencional de 265 pós-graduandos, o que representa $38 \%$ da população-alvo.

O questionário foi dividido em seis blocos. O primeiro envolveu questões referentes à identificação do curso de pós-graduação. No segundo, terceiro e quarto blocos respectivamente, foram identificados se os discentes realizam atividades paralelas ao curso de pós-graduação, o quão satisfeitos estão com suas relações pessoais e aspectos relacionados a lazer e entretenimento. As questões do quinto bloco foram relativas ao Inventário de Sintomas de Stress de Lipp, o qual define o nível de estresse por meio da quantidade de sintomas assinalada, conforme descrito na Quadro 3. Por fim, o último bloco investigou o perfil do pós-graduando, evidenciando os aspectos pessoais.

\begin{tabular}{|l|l|l|}
\multicolumn{1}{c}{ FASES DE } \\
\multicolumn{1}{c}{ ESTRESSE } & \multicolumn{1}{c|}{ QUANTIDADE DE } & \multicolumn{1}{c|}{$\begin{array}{c}\text { OCORRÊNCIA DOS } \\
\text { SINTOMAS }\end{array}$} \\
\hline Alerta & $\mathrm{x}>5$ & Últimas 24 horas \\
\hline Resistência & $3<\mathrm{x}>9$ & Última semana \\
\hline Quase-exaustão & $\mathrm{x}>8$ & Última semana \\
\hline Exaustão & $\mathrm{x}>9$ & Último mês \\
\hline
\end{tabular}

Quadro 3 Resumo das fases e sintomas de estresse.

Fonte: Vieria, Alves, e Succar Junior (2012).

O pré-teste foi aplicado em mestrandos de um dos Programas de pós-graduação. Ao fim, constataram-se pequenas dificuldades e algumas sugestões; dessa forma o instrumento foi readequado e submetido a um novo pré-teste, que resultou na versão final do questionário.

Para análise das variáveis quantitativas os dados foram tabulados no Microsoft Excel 2007®. Em seguida, utilizou-se o software Statistical Package for the Social Sciences (SPSS $\left.{ }^{\circledR}\right)$ para processar os dados. Para analisar o relacionamento entre as variáveis, elaborouse tabelas de referência cruzada. Dessa forma, foi possível traçar o perfil dos estudantes, relacionando suas características pessoais e profissionais com a fase de estresse que se encontram.

\section{RESULTADOS E DISCUSSÕES}

Nesta seção, serão apresentadas as características pessoais, os aspectos do curso de pós-graduação, as fases e os sintomas de estresse identificados nos mestrandos e doutorandos em contabilidade. 


\subsection{ASPECTOS PESSOAIS E DO CURSO DE PÓS-GRADUAÇÃO}

Dentre os respondentes, 147 são homens (55,5\%) e 118 (44,5\%) são mulheres, sendo que $13,6 \%$ possuem menos de 25 anos, $33,6 \%$ de 25 a 30 anos, $20 \% 31$ a 35 anos, $13,2 \%$ de 36 a 40 anos, 9,4\% de 41 a 45 anos e 10,2\% acima de 46 anos. Ainda, grande parte dos discentes (86\%) possuem curso de graduação em Ciências Contábeis; 217 são mestrandos $(81,9 \%)$ e 48 doutorandos $(18,1 \%) ; 173$ realizam o curso de pós-graduação em IES pública $(65,3 \%)$ e $92(34,7 \%)$ em IES privada.

Relacionando a faixa etária com o tipo de instituição, publica ou privada, percebe-se que nas IES públicas $42 \%$ dos discentes possuem de 25 a 30 anos, por outro lado, nas IES privadas somente $17 \%$ dos respondentes enquadram-se nesta faixa etária. Observa-se que os pós-graduandos com idade superior a 46 anos concentram-se nas IES privadas (23\%); em direção oposta acontece nas IES públicas, onde os mestrandos e doutorandos com idade superior a 46 anos foram os menos recorrentes (Figura 1).

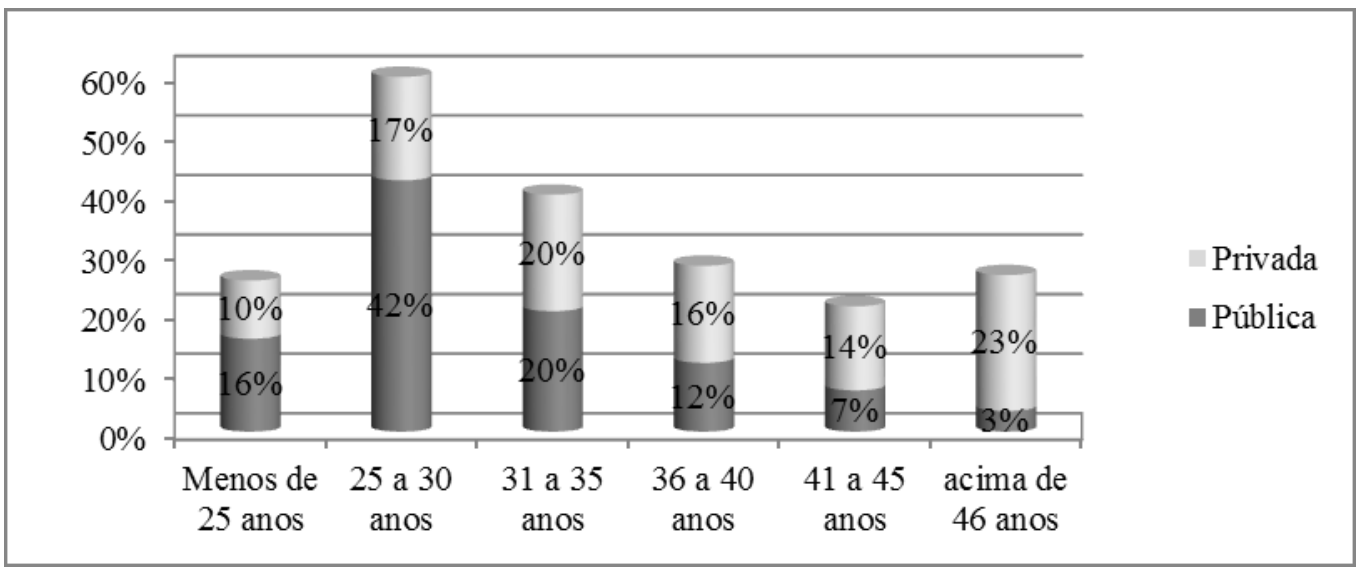

Figura 1 IES públicas e IES privadas: faixa etária. Fonte: Os autores (2013).

Dos bolsistas (36,6\%), 80\% possuem dedicação exclusiva e $12 \%$ mesmo não tendo bolsa dedicam-se exclusivamente ao curso de pós-graduação. Ao se relacionar o índice de bolsistas por instituições de ensino, observa-se que nas IES públicas a quantidade de bolsistas é bastante representativa $(82,5 \%)$ sendo que este índice é $27,1 \%$ superior às IES privadas. Com relação à dedicação exclusiva ao curso de pós-graduação, constata-se que $48 \%$ destes estudantes concentram-se nas IES públicas; em contrapartida grande parte dos estudantes das IES privadas não possuem dedicação exclusiva $(83,7 \%)$ (Tabela 1$)$. 
Tabela 1 IES públicas e IES privadas: bolsista x dedicação exclusiva

\begin{tabular}{|c|c|c|c|c|c|c|c|c|c|c|}
\hline \multirow[b]{3}{*}{ IES Pública } & \multicolumn{4}{|c|}{ Bolsista } & \multirow{3}{*}{\begin{tabular}{|l|} 
Total \\
173 \\
\end{tabular}} & \multicolumn{4}{|c|}{ Dedicação Exclusiva } & \multirow{3}{*}{\begin{tabular}{|l|} 
Total \\
173 \\
\end{tabular}} \\
\hline & \multicolumn{2}{|c|}{ Sim } & \multicolumn{2}{|c|}{ Não } & & \multicolumn{2}{|c|}{ Sim } & \multicolumn{2}{|l|}{ Não } & \\
\hline & 80 & $46,20 \%$ & 93 & $53,80 \%$ & & 83 & $48,00 \%$ & 90 & $52,00 \%$ & \\
\hline IES Privada & 17 & $18,50 \%$ & 75 & $81,50 \%$ & 92 & 15 & $16,30 \%$ & 77 & $83,70 \%$ & 92 \\
\hline Total & 97 & & 168 & & 265 & 98 & & 167 & & 265 \\
\hline
\end{tabular}

Fonte: Os autores (2013).1

Referente ao estágio do curso, 32,8\% dos pós-graduandos estão cursando disciplinas, $32,5 \%$ desenvolvendo a dissertação, $10,9 \%$ na fase de qualificação e $23,8 \%$ na fase de defesa. Foi investigado se os discentes realizavam alguma atividade profissional paralela ao mestrado ou doutorado, grande parte dos estudantes $(65,7 \%)$ responderam que desenvolvem outras atividades.

Com relação à situação conjugal, 39,6\% informaram serem solteiros, $54,7 \%$ casados e $5,7 \%$ separados ou divorciados. Destaca-se que nenhum dos respondentes relatou ser viúvo. Além disso, mais da metade dos discentes $(66,8 \%)$ não possuem filhos. No que concerne a moradia atual, $54 \%$ reside com o cônjuge, $21,5 \%$ com a família (no caso de solteiros), $14 \%$ sozinho, $10,5 \%$ mora com outras pessoas como amigos, conhecidos ou colegas.

Quanto à satisfação com as relações pessoais com amigos, parentes, conhecidos, colegas, a maioria, 39,6\%, informaram estarem satisfeito com as mesmas, por outro lado, $18,9 \%$ encontram-se insatisfeitos.

Foi investigado se os discentes realizavam atividades de lazer e entretenimento pelo menos uma vez ao mês, podendo ser assinalada na resposta mais de uma opção. Na Figura 2, são apresentados os resultados das atividades mais recorrentes, destaca-se que 779 atividades foram escolhidas pelos 265 respondentes, sendo que o lazer/entretenimento preferido pelos mestrandos e doutorandos foi a internet $(24,1 \%)$ e os que apresentaram menores índices foram teatro $(2,1 \%)$ e "balada" $(2,6 \%)$. 


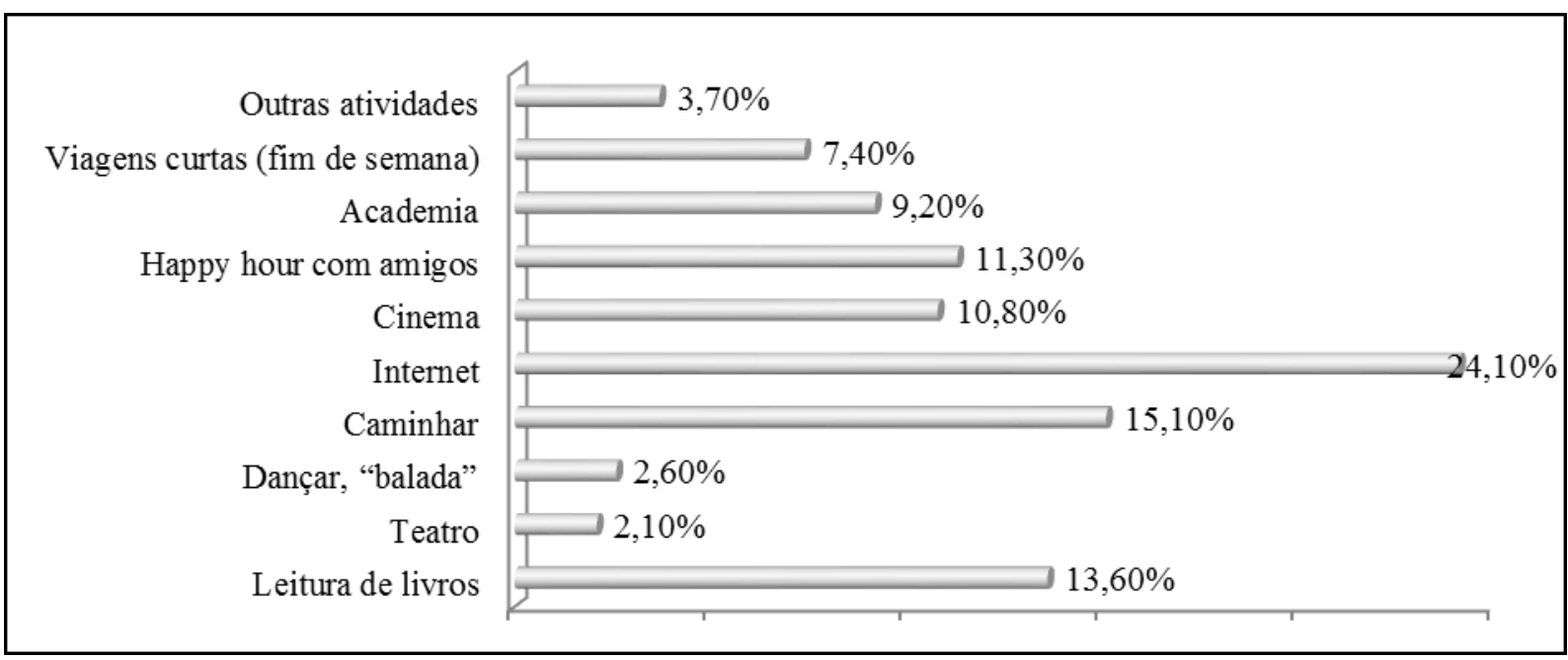

Figura 2 Atividades de lazer e entretenimento realizadas pelo menos uma vez ao mês Fonte: Os autores (2013).

Adicionalmente foi averiguado se os mestrandos e doutorandos costumam praticar atividades físicas regularmente. A partir das respostas verificou-se que 155 pós-graduandos $(58,5 \%)$ não praticam exercícios físicos com certa frequência, sobretudo em função da disponibilidade de tempo. Além disso, não foi constatada diferença significativa entre a prática ou não de exercícios físicos entre mestrandos e doutorandos, sendo que $46 \%$ dos doutorandos realizam regularmente atividades físicas, enquanto que $41 \%$ dos mestrandos realizam exercícios físicos com certa frequência. Em relação ao gênero, observa-se que 44\% dos homens praticam atividades físicas regularmente, percentual pouco acima do representado pelas mulheres, que totalizam $38 \%$.

\subsection{SINTOMAS E AS FASES DO ESTRESSE}

De acordo com os respondentes, nas últimas 24 horas os sintomas mais frequentes foram: tensão muscular (18\%), insônia (15\%), vontade súbita de novos projetos (11\%), mudança de apetite (muito ou pouco) (9\%), nó ou dor no estômago (8\%), boca seca (7\%), taquicardia (5\%), diarreia passageira (4\%), respiração ofegante $(4 \%)$, entusiasmo súbito (4\%), aumento de suadores (4\%), mãos e/ou pés frios (3\%), hipertensão súbita ou passageira (2\%).

Com relação aos sintomas mais recorrentes na última semana tem-se: cansaço constante $(12 \%)$, esquecimento (11\%), sensação de desgaste físico constante $(10 \%)$, irritabilidade excessiva (10\%), dúvidas quanto a si próprio $(8 \%)$, pensamentos sobre um só assunto (8\%), sensibilidade emotiva excessiva (7\%), diminuição da libido (6\%), mudança de apetite $(5 \%)$, mal-estar generalizado sem causa (5\%), gastrite prolongada $(5 \%)$, tontura $(4 \%)$, 
surgimento de problemas dermatológicos (4\%), formigamento nos pés/mãos $(4 \%)$, hipertensão arterial (1\%).

Os sintomas elencados como mais frequentes no último mês foram: cansaço excessivo $(10 \%)$, angústia ou ansiedade diária (9\%), irritabilidade sem causa aparente $(9 \%)$, vontade de fugir de tudo (7\%), insônia (6\%), pensamento constante sobre o mesmo assunto (6\%), sensação de incompetência em todas as áreas (6\%), perda do senso de humor (6\%), apatia, vontade de fazer nada, depressão (6\%), hipersensibilidade emotiva $(5 \%)$, pesadelos $(4 \%)$, formigamento nos pés/mãos $(3 \%)$, dificuldades sexuais $(3 \%)$, problemas dermatológicos prolongados $(3 \%)$, tiques nervosos $(3 \%)$, mudança extrema de apetite $(3 \%)$, taquicardia $(2 \%)$, tontura frequente $(2 \%)$, diarreias frequentes $(2 \%)$, impossibilidade de trabalhar $(2 \%)$, hipertensão arterial confirmada (1\%).

A partir da frequência dos sintomas descritos, foi possível identificar se os mestrandos e doutorandos apresentam sintomas de estresse, e caso estes fossem identificados, foi possível a partir de sua incidência verificar em qual a fase que o mesmo encontra-se. Ressalta-se que os sintomas das últimas 24 horas definem a fase de alerta, os sintomas da última semana as fases de resistência e quase-exaustão, e os sintomas do último mês a fase de exaustão. Dentre os pós-graduandos, 46 apresentaram sintomas da fase de alerta, 100 da fase de resistência, 47 da fase de quase-exaustão e 69 da fase de exaustão.

Entre os mestrandos, 39 estavam na fase de alerta, 82 na fase de resistência, 39 na fase de quase-exaustão e 55 na fase de exaustão. Com relação aos doutorandos que participaram do estudo, 7 estão na fase de alerta, 18 na fase de resistência, 8 na fase de quase-exaustão e 14 na fase de exaustão, logo há indícios que os mestrandos são mais estressados que os doutorandos (Tabela 2).

Tabela 2 Fases de estresse: mestrado x doutorado.

\begin{tabular}{|c|c|c|c|c|c|c|c|c|c|c|c|c|c|c|c|c|c|}
\hline \multirow[b]{2}{*}{ Mestrado } & \multicolumn{2}{|c|}{$\begin{array}{l}\text { Sem } \\
\text { Sintomas }\end{array}$} & \multicolumn{2}{|c|}{$\begin{array}{l}\text { Fase de } \\
\text { Alerta }\end{array}$} & \multirow{2}{*}{\begin{tabular}{|l|} 
Total \\
217
\end{tabular}} & \multicolumn{2}{|c|}{$\begin{array}{l}\text { Sem } \\
\text { Sintomas }\end{array}$} & \multicolumn{2}{|c|}{$\begin{array}{l}\text { Fase de } \\
\text { Resistência }\end{array}$} & \multicolumn{2}{|c|}{$\begin{array}{l}\text { Fase de } \\
\text { Quase- } \\
\text { Exaustão }\end{array}$} & \multirow{2}{*}{$\begin{array}{l}\text { Total } \\
217\end{array}$} & \multicolumn{2}{|c|}{$\begin{array}{l}\text { Sem } \\
\text { Sintomas }\end{array}$} & \multicolumn{2}{|c|}{$\begin{array}{l}\text { Fase de } \\
\text { Exaustão }\end{array}$} & \multirow{2}{*}{$\begin{array}{l}\text { Total } \\
217\end{array}$} \\
\hline & 178 & $82 \%$ & 39 & $18 \%$ & & 96 & $44 \%$ & 82 & $38 \%$ & 39 & $18 \%$ & & 162 & $75 \%$ & 55 & $25 \%$ & \\
\hline Doutorado & 41 & $85 \%$ & 7 & $15 \%$ & 48 & 22 & $46 \%$ & 18 & $38 \%$ & 8 & $17 \%$ & 48 & 34 & $71 \%$ & 14 & $29 \%$ & 48 \\
\hline Total & 219 & & 46 & & 265 & 118 & & 100 & & 47 & & 265 & 196 & & 69 & & 265 \\
\hline
\end{tabular}

Fonte: Os autores (2013). 
Também foi constatado quem apresenta maior recorrência de estresse, os homens ou as mulheres. Pela Figura 3 observa-se claramente que as mulheres são mais estressadas em todas as fases comparativamente aos homens, com destaque para as fases de quase-exaustão e exaustão, onde os índices de estresse no sexo feminino chegam a ser $20 \%$ e $25 \%$ superior ao sexo masculino, respectivamente.



Figura 3 Fases de estresse: homem x mulher.

Fonte: Os autores (2013).

Não houve diferenças relevantes com relação ao nível de estresse em pós-graduandos de IES públicas e privadas, com resalva para a fase de resistência, que apresentou a maior oscilação, $40 \%$ dos discentes de IES públicas e 34\% de IES privada.

Relacionando a faixa etária com o nível de estresse, observou-se que os pósgraduandos com idade entre 41 a 45 anos prevalecerem na fase de alerta, resistência e exaustão. Já a fase de quase-exaustão teve maior incidência de discentes com idade menor que 25 anos. Ressalta-se que nenhum dos pós-graduandos com idade superior a 46 anos apresentaram estresse nas fases de quase-exaustão e exaustão (Tabela 3).

Tabela 3 Fases de estresse: faixa etária.

\begin{tabular}{|c|c|c|c|c|c|c|c|c|c|c|c|c|c|c|c|c|c|}
\hline \multirow[b]{2}{*}{$\begin{array}{l}\text { Menos de } 25 \\
\text { anos }\end{array}$} & \multicolumn{2}{|c|}{$\begin{array}{l}\text { Sem } \\
\text { Sintomas }\end{array}$} & \multicolumn{2}{|c|}{$\begin{array}{l}\text { Fase de } \\
\text { Alerta }\end{array}$} & \multirow{2}{*}{$\begin{array}{l}\text { Total } \\
36\end{array}$} & \multicolumn{2}{|c|}{$\begin{array}{l}\text { Sem } \\
\text { Sintomas }\end{array}$} & \multicolumn{2}{|c|}{$\begin{array}{l}\text { Fase de } \\
\text { Resistência }\end{array}$} & \multicolumn{2}{|c|}{$\begin{array}{l}\text { Fase de } \\
\text { Quase- } \\
\text { Exaustão }\end{array}$} & \multirow{2}{*}{$\begin{array}{l}\text { Total } \\
22\end{array}$} & \multicolumn{2}{|c|}{$\begin{array}{l}\text { Sem } \\
\text { Sintomas }\end{array}$} & \multicolumn{2}{|c|}{$\begin{array}{l}\text { Fase de } \\
\text { Exaustão }\end{array}$} & \multirow{2}{*}{\begin{tabular}{|l|} 
Total \\
36
\end{tabular}} \\
\hline & 28 & $78 \%$ & 8 & $22 \%$ & & 14 & $39 \%$ & 12 & $33 \%$ & 10 & $28 \%$ & & 25 & $69 \%$ & 11 & $31 \%$ & \\
\hline 25 a 30 anos & 69 & $78 \%$ & 20 & $22 \%$ & 39 & 33 & $37 \%$ & 36 & $40 \%$ & 20 & $22 \%$ & 56 & 61 & $69 \%$ & 28 & $31 \%$ & 89 \\
\hline 31 a 35 anos & 47 & $89 \%$ & 6 & $11 \%$ & 3 & 25 & $47 \%$ & F & $\%$ & 9 & $17 \%$ & 28 & 41 & $77 \%$ & 12 & $23 \%$ & 53 \\
\hline 36 a 40 anos & 32 & $91 \%$ & 3 & $9 \%$ & 35 & 21 & $60 \%$ & 9 & $26 \%$ & 5 & $14 \%$ & 14 & 25 & $71 \%$ & 10 & $29 \%$ & 35 \\
\hline 41 a 45 anos & 19 & $76 \%$ & 6 & $24 \%$ & 25 & 0 & $36 \%$ & 13 & $52 \%$ & 3 & $12 \%$ & 16 & 17 & $8 \%$ & 8 & $32 \%$ & 25 \\
\hline $\begin{array}{l}\text { Acima de } 46 \\
\text { anos }\end{array}$ & 24 & $89 \%$ & 3 & $11 \%$ & 27 & 16 & $59 \%$ & 11 & $41 \%$ & 0 & - & 11 & 27 & $100 \%$ & 0 & - & 27 \\
\hline Total & 219 & & 46 & & 265 & 118 & & 100 & & 47 & & 265 & 196 & & 69 & & 265 \\
\hline
\end{tabular}

Fonte: Os autores (2013) 
Relacionou-se também o nível de estresse com o estágio do curso. Pela Figura 4, observa-se que a fase de resistência apresenta os maiores índices de estresse, e de acordo com os respondentes o período mais estressante do curso de pós-graduação é a fase de qualificação (52\%). Por outro lado, os sintomas menos recorrentes referem-se à fase de quase-exaustão.

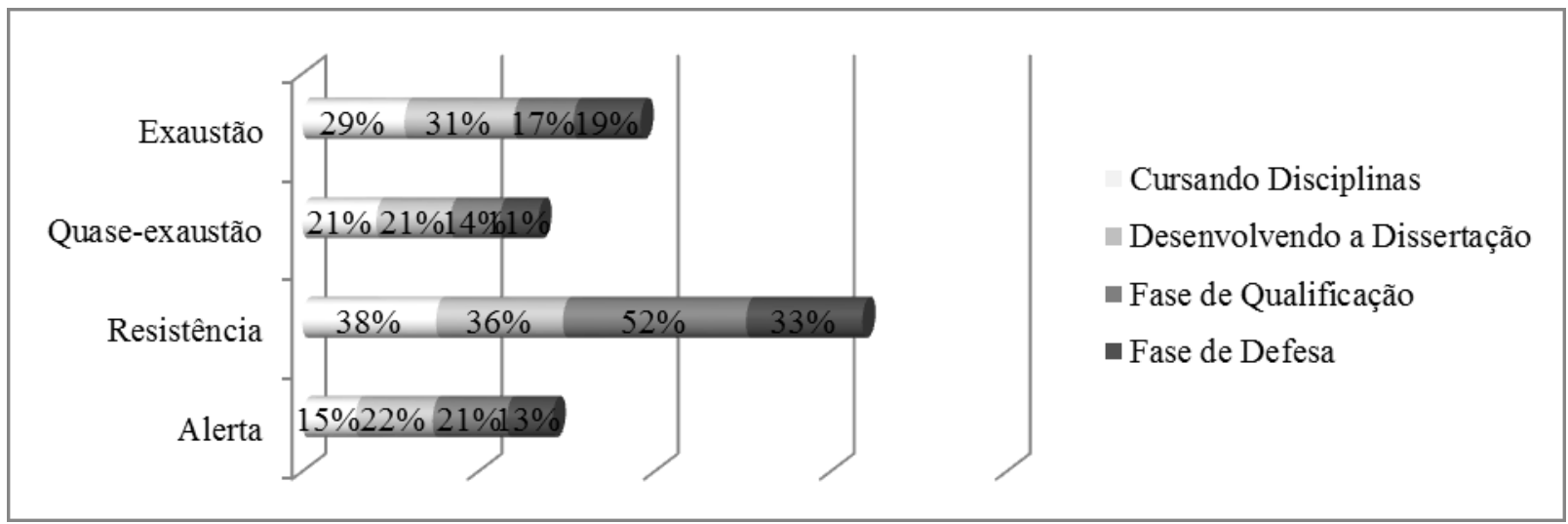

Figura 4 Fases de estresse: estágio do curso de pós-graduação. Fonte: Os autores (2013).

A situação conjugal dos respondentes evidenciam que na fase de alerta os mais estressados são os solteiros (19\%) e os menos estressados os separados ou divorciados (7\%). Na fase de exaustão ocorre uma inversão, os casados passam a ser a categoria que apresenta menores sintomas de estresse (36\%) (Figura 5).

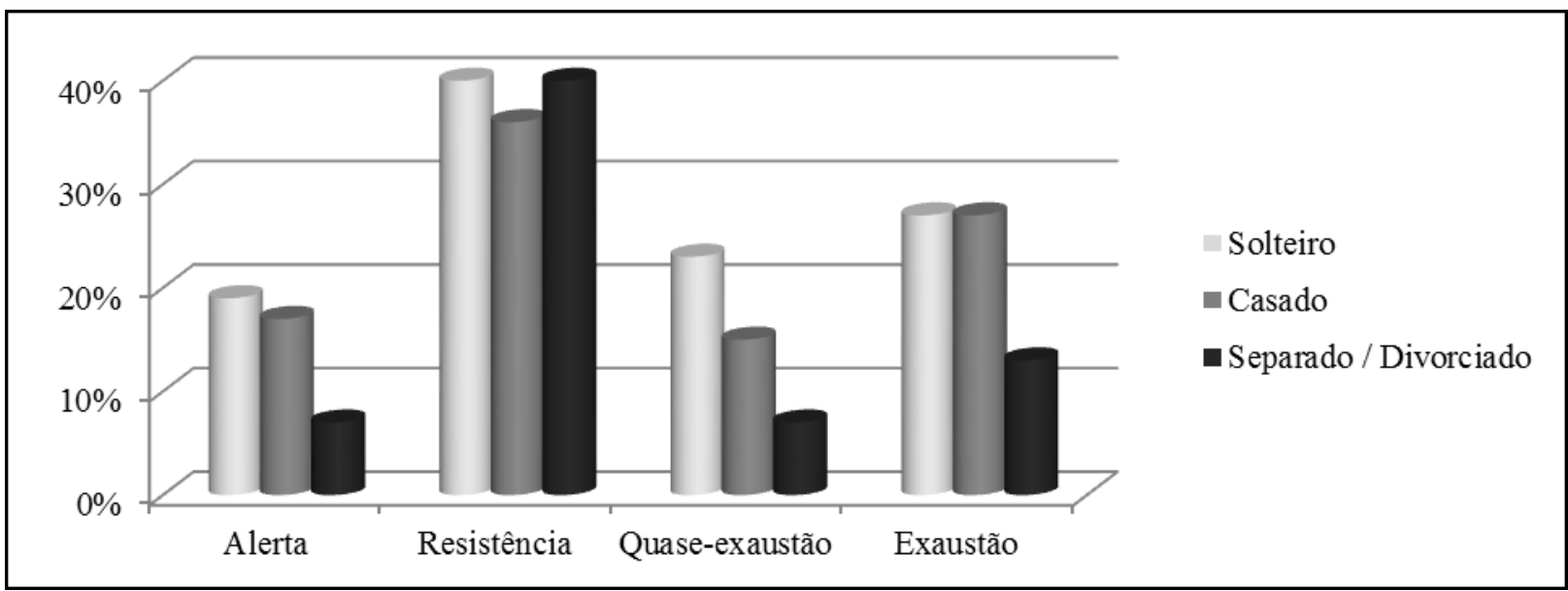

Figura 5 Fases de estresse: situação conjugal. Fonte: Os autores (2013).

$\mathrm{Na}$ fase de quase-exaustão, mais uma vez, os solteiros (23\%) são os mais estressados, seguidos pelos casados (15\%) e separados ou divorciados $(7 \%)$. Na última fase - exaustão - 
$27 \%$ dos solteiros e casados possuem sintomas de estresse, enquanto que somente $13 \%$ dos separados ou divorciados apresentaram sintomas.

\section{CONCLUSÕES E RECOMENDAÇÕES}

A busca por capacitação, inclusive em cursos Scricto Sensu reflete o mercado competitivo vivido atualmente. No entanto, o ingresso à pós-graduação sugere um processo de adaptação devido à mudança de hábitos e rotinas. O processo adaptativo pode desencadear o estresse, uma vez que o organismo reage quando se encontra em situações não habituais.

Essa reação pode ser observada pela ocorrência de vários sintomas como insônia, cansaço constante, entre outros, que, dependendo da quantidade e frequência, elenca o indivíduo em quatro fases de estresse, conforme sugerido por Lipp (2000a), sendo elas: fase de alerta; fase de resistência; fase de quase-exaustão; e, fase de exaustão.

Diante disso, o estudo buscou identificar os sintomas de estresse apresentados por mestrandos e doutorandos em Ciências Contábeis no Brasil, elencando-os nas respectivas fases propostas por Lipp (2000a). Após a análise dos dados observou-se que em todas as fases a maioria dos estudantes não apresentaram estresse, sendo que 219 respondentes não demonstraram sinais de estresse na fase de alerta, 118 na fase de resistência e quase-exaustão, e 196 na fase de exaustão. Um dos motivos para a alta quantidade de alunos sem estresse pode ser atribuído a nova rotina imposta pela sociedade, em que, desde cedo as pessoas aprendem a lidar com uma multiplicidade de tarefas como colégio, cursos, entre outras responsabilidades.

Dentre os respondentes com algum grau de estresse, observou-se que em todas as fases os mestrandos apresentaram índices mais elevados que os doutorandos. Uma provável explicação para esta constatação refere-se ao processo adaptativo. A mudança de rotina da graduação para o mestrado é bem mais intensa do que do mestrado para o doutorado, pois o último possui características semelhastes ao primeiro.

Verificou-se também que as mulheres demonstraram-se mais estressadas do que os homens em todas as fases. Possatti e Dias (2002) atribuem o alto nível de estresse das mulheres à multiplicidade de papéis por elas desempenhada como estudo, trabalho, casa, filhos, entre outras responsabilidades. Além disso, os achados do estudo demonstraram que as mulheres praticam menos atividades físicas quando comparadas aos homens, o que pode justificar maiores níveis de estresse. 
Dentre os estágios do curso de pós-graduação: cursando disciplinas; desenvolvendo a dissertação; fase de qualificação; e, fase de defesa, constatou-se maior incidência de estresse na fase de qualificação, possivelmente em função dos prazos estabelecidos e das inúmeras tarefas a serem realizadas neste período.

Entre os sintomas que mais se destacaram em cada fase tem-se: fase de alerta - tensão muscular (18\%), insônia (15\%) e vontade súbita de novos projetos $(11 \%)$; fase de resistência e quase-exaustão - cansaço constante (12\%), problemas com a memória (11\%), sensação de desgaste físico constante (10\%) e irritabilidade excessiva (10\%); fase de exaustão - cansaço excessivo (10\%), angústia ou ansiedade diária (9\%) e irritabilidade sem causa aparente $(9 \%)$.

Como forma de reduzir os sintomas provocados pelo estresse e contribuir para o bemestar e a qualidade nos estudos, sugere-se a prática de atividades físicas e dedicação a momentos de lazer. Por fim, recomenda-se a realização de novas pesquisas com o intuito de aprofundar o entendimento sobre o estresse em pós-graduandos, sendo que estudos qualitativos poderão auxiliar na compreensão sobre os fatores causadores de estresse nesta população.

\section{REFERÊNCIAS}

ARANTES, M. A. de A. C.; VIEIRA, M. J. F.. Estresse. São Paulo: Casa do Psicólogo, 2002.

CALAIAS, S. L.; ANDRADE, L. M. B. de; LIPP, M. E. N.. Diferenças de sexo e escolaridade na manifestação de stress em adultos e jovens. Psicologia: reflexão e crítica, v. 16. n. 2, p. 257-263, 2003.

CAPES - Coordenação de Aperfeiçoamento de Pessoal de Nível Superior. Ficha de Avaliação do Programa. Critérios de Avaliação Triênio 2004-2006, Programas/Cursos Acadêmicos - Administração, Contabilidade e Turismo. Disponível em: $<$ http://www.capes.gov.br/images/stories/download/avaliacao/CA2007_AdministracaoTurism o.pdf>. Acesso em: 05 jan. 2013.

- Coordenação de Aperfeiçoamento de Pessoal de Nível Superior. Relação de

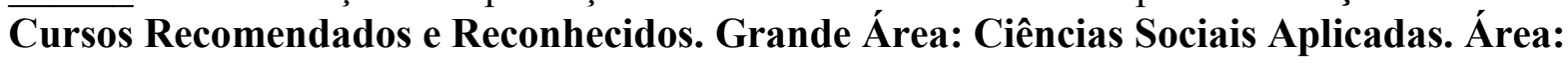
Administração. Disponível em:

$<$ http://conteudoweb.capes.gov.br/conteudoweb/ProjetoRelacaoCursosServlet?acao=pesquisa rIes\& codigoArea $=60200006 \&$ descricaoArea $=\mathrm{CI} \%$ CANCIAS + SOCIAIS + APLICADAS $+\& d e$ scricaoAreaConhecimento $=$ ADMINISTRA $\% \mathrm{C} 7 \% \mathrm{C} 3 \mathrm{O} \&$ descricaoAreaAvaliacao $=\mathrm{ADMINIS}$ TRA $\% \mathrm{C} 7 \% \mathrm{C} 3 \mathrm{O} \% 2 \mathrm{C}+\mathrm{CI} \% \mathrm{CANCIAS}+\mathrm{CONT} \% \mathrm{C} 1 \mathrm{BEIS}+\mathrm{E}+\mathrm{TURISMO}>$. Acesso em: 05 jan. 2013. 
IGARASHI, D. C. C.; ENSSLIN, S. R.; ENSSLIN, L.; PALADINI, E. P.. A qualidade do ensino sob o viés da avaliação de um programa de pós-graduação em contabilidade: proposta de estruturação de um modelo híbrido. Revista Administração, v. 43, n. 2, p. 117-137, 2008.

LANGSTON, A. C.; CANTOR, N.. Social anxiety and social constraint: When making friends is hard. Journal of Personality and Social Psychology, v. 56, n. 4, p. 649-661,1989.

LIPP, M. E. N.. O inventário de Sintomas de Stress para Adultos de Lipp (ISSL). São Paulo: Casa do Psicólogo, 2000.

, M. E. N..O stress esta dentro de você. O que eu tenho é stress? De onde ele vem?. São Paulo: Contexto, 2000. p. 9-18.

LIPP, M. E. N.; MALAGRIS, L. E. N.. O stress emocional e seu tratamento. In: B. Rangé (Org). Psicoterapias cognitivo-comportamentais: um diálogo com a psiquiatria (p.475-490). Porto Alegre: Artmed, 2001.

MALAGRIS, L. E. N.; FIORITO, A. C. C.. Avaliação do nível de stress de técnicos da área de saúde. Estudos de Psicologia, v. 23, n. 4, p. 391-398, out./dez., 2006.

MALAGRIS, L. E. N.; SUASSUNA, A. T. R.; BEZERRA, D. V.; HIRATA, H. P.; MONTEIRO, J. L. F.; SILVA, L. R. da; LOPES, M. da C. M.; SANTOS, T. S.. Níveis de estresse e características sociobiográficas de alunos de pós-graduação. Psicologia em Revista, v. 15, n. 1, p. 184-203, 2009.

MARGIS, R.; PICON, P.; COSNER, A. F.; SILVEIRA, R. O.. Relação entre estressores, estresse e ansiedade. Revista de Psiquiatria do Rio Grande do Sul, v. 25, n. 1, p. 65-74, 2003.

MARTINS, E.; IUDÍCIBUS, S. de. 30 anos do doutorado em contabilidade. Revista Contabilidade e Finanças, Ed. 30 Anos de Doutorado, p. 7-8, 2007.

POSSATTI, I. C.; DIAS, M. R.. Multiplicidade de papéis da mulher e seus efeitos para o bem-estar psicológico. Psicologia: Reflexão e Crítica, v. 15, n. 2, p. 293-301, 2002.

PERES, C. M.. Avaliação da qualidade de vida e dos sintomas de estresse em mulheres menopausadas com disfunção da articulação temporomandibular, 2008. 93 f. Dissertação (Mestrado em Educação Física). Universidade Estadual de Campinas - Unicamp, Campinas, 2008.

SANTOS, A. F.; ALVES JUNIOR, A.. Estresse e estratégias de enfrentamento em mestrandos de ciências da saúde. Psicologia: Reflexão e Crítica, v. 20, n.1, p. 104-113, 2007.

SAVÓIA, M. G.. Escala de eventos vitais e de estratégias de enfrentamento (coping). Revista de Psiquiatria Clínica, n. 26, v. 2, p. 56-67, 1999. 
SCHILlingS,A. I.. Processo de estresse em mestrandos. 2005. 110f. Dissertação (Mestrado em Psicologia) - Centro de Filosofia e Ciências Humanas, Universidade Federal de Santa Catarina, Florianópolis, 2005.

SELYE, H.. Stress: atenção da vida. São Paulo: Ibrasa, 1956.

SILLAS, E. P.; FREITAS, E. M.; ESPEJO, M. M. S. B.; PACHECO, V.. Mulheres contabilistas: um estudo do nível de estresse e seus sintomas nas profissionais atuantes no estado do Paraná. In: Congresso Anpcont, 5., 2011, Vitória. Anais..., Vitória, 2011.

SOARES, S. V.; RICHARTZ, F.; MURCIA, F. D. R.. Ranking da pós-graduação em contabilidade no Brasil: análise dos programas de mestrado com base na produção científica em periódicos acadêmicos no triênio 2007-2009. In: Congresso Anpcont,5., 2011, Vitória. Anais..., Vitória, 2011.

TRZESNIAK, P.. Qualidade e produtividade nos programas de pós-graduação: A disciplina seminário de dissertação. Revista Brasileira de Pós-Graduação, n. 1, p. 111-125, jul., 2004.

VELLOSO, J.. Mestres e doutores no país: destinos profissionais e políticas de pósgraduação. Cadernos de Pesquisa, v. 34, n. 123, p. 583-611, 2004.

VIERIA, S. S. da C.; ALVES, F. J. dos S.; SUCCAR JUNIOR, F.. Análise do nível de estresse do profissional de Contabilidade. Revista Contemporânea de Contabilidade, v. 9, n.18, p. 103-118m jul./dez., 2012.

VOLTARELLI, J. C.. Estresse e produtividade acadêmica (Editorial). Revista Medicina Ribeirão Preto, v. 4, n. 35, p. 451-454, 2002. 